\title{
How Vocational Delay of Gratification Affects Employees' Job Performance: Organizational Climate as a Moderator
}

\author{
Qichao He, Qiao An, Menghan Li \\ School of Government, Beijing Normal University, Beijing, China \\ Email: chao.adam@163.com
}

Received 7 October 2015; accepted 26 October 2015; published 29 October 2015

Copyright (C) 2015 by authors and Scientific Research Publishing Inc.

This work is licensed under the Creative Commons Attribution International License (CC BY). http://creativecommons.org/licenses/by/4.0/

c) (†) Open Access

\begin{abstract}
Vocational Delay of Gratification stresses employees will overcome the impulse and temptation of immediate gratification to achieve long-term career goals, which provides a new perspective to examine and explain individual's career development. This paper aims at identifying the influence mechanism of Vocational Delay of Gratification on employee's job performance and the role of organizational climate among the triadic relationship. The analysis result of Structural Equation Model about 350 sample data showed that Vocational Delay of Gratification had a significantly positive effect on job performance, while organizational climate acted as a positive moderator between Vocational Delay of Gratification and employee's job performance. Therefore, it is highly recommended that companies should pay attention to the state of employee's vocational delay of gratification, satisfy their psychological need as to increase job satisfaction and improve job performance.
\end{abstract}

\section{Keywords}

Vocational Delay of Gratification, Organizational Climate, Job Satisfaction, Job Performance

\section{Introduction}

As a saying goes, the greatness is achieved through diligence and retarded by laziness, while the deed is accomplished through thinking and destroyed by idleness. With the accelerated pace of the times, how can the practitioners control themselves, restrain momentary desires, sacrifice short-term personal happiness and throw themselves into organizational work to gain recognition, job promotion and career leap process is particularly important. In light of this phenomenon, scholars have raised an important concept, namely Vocational Delay of Grati-

How to cite this paper: He, Q.C., An, Q. and Li, M.H. (2015) How Vocational Delay of Gratification Affects Employees' Job Performance: Organizational Climate as a Moderator. Journal of Service Science and Management, 8, 766-772. 
fication. Reynolds and Schiffbauer, from the perspective of career development, defined Vocational Delay of Gratification as an ability that individual keeps the action which conducive to achieving long-term career options and objectives, while the short-term instant gratification alternative still exists [1]. "Do not require fast and do not covet a small profit. More haste less speed, and with one's eyes fixed on petty profits, one can hardly succeed in great ventures", two thousand years ago, Confucius has made a lively overview about Vocational Delay of Gratification in Confucius' Analects XIII [2]. Nowadays, markets changed a lot and business competition intensified. In this case, personal attitude may become impetuous and people are confused on career goals. What's more, organization sometimes neglects staff training and directing, which often makes employees hard to restrain material desires, calm down and devote themselves to the work, thus not only make the inimical emotions to the profession increased, but make their job performance beaten up by the instant pleasure. According to the study of Borman and Motowidlo [3], job performance contains two dimensions, namely task performance and contextual performance. Task performance is directly related to the output of work and it can be directly evaluated. Different from task performance, contextual performance is a series of voluntary, interpersonal, organizational or group behavior, these behaviors create a good psychological and social environment, which is conducive to achieving overall task of the organization. Thus, exploring how Vocational Delay of Gratification influences employees' job performance is meaningful for both employees and organizations. Because the relationship between Vocational Delay of Gratification and job performance will help employees develop career strategies and organizations improve performance. Moreover, under the dual effect of the current open market environment and the "people-oriented" trends, employees' individual consciousness and the desire of accomplishments are increasing. They are no longer satisfied with a considerable salary, but paying more attention to self-realization and being respected in the organization. Therefore, only the "vocational delay" was "gratified" in a harmonious internal environment can it acts as an impetus in the organization.

From the view of the organizational climate, this paper found that the relationship among Vocational Delay of Gratification, employees' job performance and job satisfaction is also influenced by environmental factors, which largely made up for the previous deficiency of focusing merely on personality factors and ignoring the environment variables. It is recommended companies should pay more attention to employee's Vocational Delay of Gratification situation, improve the job satisfaction by meeting their psychological needs, thereby promoting job performance. This paper attempts to identify the influence mechanism of Vocational Delay of Gratification on employees' job performance and the role of organizational climate among the triadic relationship, which has much theoretical and practical implications.

\section{Theoretical Background and Hypotheses}

\subsection{Vocational Delay of Gratification and Employee's Job Performance}

Job performance refers to the related behaviors which can be observed through certain means that employees exhibited to achieve organizational goals in the work process [3] [4]. According to the theory of cognitive affective system by Mischel, the event we encounter will interact with a complex cognitive-affective system, then ultimately determine our behavior. Delay of gratification tendencies are based on expectations of possible reward and could predict one's adaptive behavior. For different level of delay of gratification, there are differences in the degree of adaptation. The employee who goes after short-term interests are more inclined to slack and resulting in low performance, while the ones who are willing to expect long-term interests of company ,more tend to maintain a high career satisfaction and make more substantial performance. Existing studies have also supported the above reasoning, About the topic of professional ethics, Miller et al. found college students are more willing to delay the gratification in the work than people with the same age who have a job, and people who have higher level of delay of gratification will gain more outstanding performance [5]. Some researchers have found Vocational Delay of Gratification will be positively related to job performance, job involvement, occupational commitment \& job satisfaction [6]-[12]. Zhang found Vocational Delay of Gratification can increase civil servants' job performance [13]. Based on this, we put forward the following hypothesis:

H1: Vocational Delay of Gratification promotes employees' job performance.

\subsection{Organizational Climate and Employee's Job Performance}

Main effects model theory contends that organizational climate has a directly positive effect on some individual 
and organizational performance, which means organizational climate plays a direct role in promoting individual behavior and performance. Meanwhile, combined with existing researches, factors affecting employee's job performance include organizational climate, job motivation, individuals' personality, general efficacy and so on. Among these factors, employees' personality characteristics has long-term invariance, even if the task environment has changed, the impact of personality traits on tasks also have stability, while organizational climate can be adjusted in a short time and can be quickly perceived by the staff [14].

Because the employees' perception to the organizational climate can influence the dimensions of organizational climate and then will affect employee's job performance [15]. Shore and Wayne empirically found three dimensions of organizational climate ,namely organizational friendly climate, innovative atmosphere and fair atmosphere, will have a significant influence on employees' involvement and job performance [16]. Pan et al. explored the relationship between organizational climate of and teacher's job performance, and found that school's organizational climate and teacher's job performance was significantly related, indicating that the school organizational climate is a good predictive factor to teacher's job performance [17]. In addition, Wang found, through structural equation model ,that organizational climate not only influence employees' job performance by self-efficacy, satisfaction and organizational commitment, but also through influencing employees' self-efficacy to affect their satisfaction and organizational commitment, and then affect their job performance [14]. Based on this, we put forward the following hypothesis:

\section{H2: Organizational climate promotes employees' job performance.}

\subsection{Organizational Climate Act as a Moderator}

According to Cognitive-affective system theory, human and environmental factors are actually connected and interacted with each other, and a variety of external factors are affecting self-regulation behaviors. Vocational Delay of Gratification reflects staff's self-control abilities, attitudes and behaviors of individuals and organizations must also be understood from the perspective of their interaction with the environment [18]. Because employees can perceive the practices, procedures and behaviors which be expected, supported and rewarded together [19], when the individuals' perceptions reach some level of consistency in the same organization, these common perceptions will gradually develop into a organizational climate. Organizational climate have a significant impact on the effectiveness of human resource management, such as job satisfaction and work efficiency, because it conveys value, attitude and behavior that the organization expected. In addition, the organizational climate will also have a significant impact on organizational effectiveness, such as members' organizational commitment and collective identity. Therefore, employee's job performance is influenced by the Vocational Delay of Gratification, and organizational climate plays a moderating role. Compared to the organizational climate that is indifferent, prejudiced and without seeking change, the relationship between employee's Vocational Delay of Gratification and job performance will be strengthened in a harmonious interpersonal relationship and a fair, continuous innovational work environment. Employees will perceive whether the current organizational climate is conducive to realizing their original intentions when they decided to have vocational delay of gratification. How the cognition to organizational climate tally with the expectancy of achieving delay of gratification, will lead to employees' high or low satisfaction in emotion and changes in the job performance in behavior. Based on this, we put forward the hypothesis:

H3: Organizational climate acts as a moderator between Vocational Delay of Gratification and job performance.

\section{Methods}

\subsection{Data and Sample}

We collected date from employees from the companies in Beijing and Shanghai. According to the list of Top Chinese 500 Companies, this paper selected 4 companies randomly. We issued 100 electronic questionnaires to functional staffs of each company. The total of 400 self-report questionnaires were issued and 380 of them were collected, among which 350 were actually valid. As a result, the valid response rate were $87.5 \%$. In the 350 valid samples, $44 \%$ were males and $56 \%$ were females. In terms of their age, about $0.1 \%$ of the participants didn't reach 20 years old, $43.4 \%$ were between $20 \%$ to 29 , $33.5 \%$ were between $30 \%$ to $39 \%$ and $21.9 \%$ were over 40 . In terms of their education background, about $23.1 \%$ of the participants had vocational degree and $29.9 \%$ had a 
lower degree, $30.7 \%$ had bachelor degree, $6.8 \%$ had master degree and $9.6 \%$ had doctor degree.

\subsection{Measures}

\section{- Vocational Delay of Gratification}

This paper utilize the Vocational Delay of Gratification scale from the Multidimensional Work Ethic Profile (MWEP) developed by Miller et al. [5]. All responses were recorded on a 6-pointLikert-type scale with $1=$ (strongly disagree) to $6=$ (strongly agree), and the Cronbach's $\alpha$ coefficient for this scale was 0.85 .

\section{- Organizational Climate}

To evaluate the organizational climate, we adopted the scale from Gee-Woo Bock [20], which contained 12 items. All responses were recorded on a 6-point Likert-type scalewith $1=$ (strongly disagree) to $6=$ (strongly agree), and the Cronbach's $\alpha$ coefficient for this scale was 0.872 .

\section{- Job Performance}

For this part , this study use the scale designed by Borman and Motowidlo [4], which contained 2 dimensions, task performance and contextual performance, and the Cronbach's $\alpha$ coefficient was 0.94 .

\section{- Control variables}

Gender, working experience, maritalstatus and highest education were controlled. These variables were presented as following: gender, 0 = male, 1 = female; working experience, $1=$ " $\leq 3 \mathrm{y}$ ”, 2 = " 3 - 5 y", 3 = "6 - 10 y", 4 = " $\geq 10 \mathrm{y}$ ”; marital status: 1 = unmarried, 2 = married, 3 = others (like divorced or widowhood);highest education: 1 = vocational degree or lower, 2 = bachelor degree, 3 = master degree, 4 = doctor degree.

\subsection{Common Variance Checking}

To reduce the homologous error, we explained in the guidance instructions that the questionnaire was an anonymous survey with no right or wrong answers, and we ensure that the results will not unveil any personal information. Therefore, participants could feel safe and provide their most honest answers without worrying situations before or after. In addition, this study also used Harman'sone-factor test to verify the degree of homology error of each researched variable. The results showed that 13 factors altogether explain $63.45 \%$ of the total variance, the largest single factor explains $15.78 \%$ of the total variance, and there was no single factor to explain most of the variation, indicating no serious common variance.

\subsection{Statistical Analysis}

After data collation, firstly, this article utilizes SPSS 19.0 to conduct correlation analysis in order to explore the relationship among Vocational Delay of Gratification, job performance and organizational climate. Then, we employ Structural Equation Model and Path analysis to further explore the relationship and verify the results of correlation analysis by AMOS 20.0.

\section{Results}

\subsection{Descriptive Statistics and Correlation Analysis}

Table 1 shows the mean values of each variable and the correlation coefficient. Neither mean values nor standard deviation (SD) shows abnormal data. Based on correlation analysis, education positively impacts the Voca-

Table 1. Mean of variable, SD and pearson correlation coefficient.

\begin{tabular}{lccccccc} 
& Mean & SD & 1 & 2 & 3 & 4 & 5 \\
\hline 1. Gender & 1.53 & 0.500 & & & & & \\
2. Marriage & 1.58 & 0.494 & $-0.265^{* *}$ & & & & \\
3. Education & 1.71 & 0.605 & $-0.106^{*}$ & $0.159^{* *}$ & & & \\
4. Vocational Delay of Gratification & 3.75 & 0.969 & 0.033 & 0.035 & $0.090^{*}$ & & \\
5. Job Performance & 4.09 & 0.845 & -0.011 & 0.056 & 0.067 & $0.752^{* * *}$ \\
6. Organizational Climate & 4.01 & 0.767 & -0.059 & 0.044 & $0.102^{*}$ & $0.735^{* * *}$ & $0.750^{* * *}$ \\
\hline
\end{tabular}

${ }^{* *}$ Correlation is significant at the 0.01 level (2-tailed); ${ }^{*}$ Correlation is significant at the 0.05 level (2-tailed). 
tional Delay of Gratification and organizational climate. Meanwhile, Vocational Delay of Gratification promotes the development of both organizational climate $(r=0.735, \mathrm{p}<0.001)$ and job performance $(\mathrm{r}=0.752, \mathrm{p}<0.001)$. Besides, organizational climate also positively impacts the job performance $(r=0.750, p<0.001)$. Therefore, Hypothesis 1 \& 2 are validated.

\subsection{The Path Analysis of Vocational Delay of Gratification and Organizational Climate's Effect on Job Performance}

To further explore the mechanism of impact path on how Vocational Delay of Gratification affects employee's job performance, this study used Structural Equation Model to further verify the results of correlation analysis. Model fit indicators were shown in Table 2. Criteria of the index are as follows: $\mathrm{X}^{2} / \mathrm{df}$ less than 3 indicates that the model fits well, CFI, TLI, IFI greater than 0.8 indicate that the model fits well. The RMSEA lower than 0.08 also indicates a good model fit. As can be seen from Table 2, various fit indices indicate that the model fits well.

The results shown in Figure 1, the results indicate both Vocational Delay of Gratification and organizational climate significantly and positively affect job performance $(\beta=0.69, \mathrm{p}<0.01) \&(\beta=0.68, \mathrm{p}<0.01)$. Meanwhile, interaction term (Vocational Delay of Gratification $\times$ Organizational Climate) positively impact job performance $(\beta=0.40, \mathrm{p}<0.01)$. Thus, organizational climate acts as a moderator between Vocational Delay of Gratification and job performance, Hypothesis 3 can be validated.

\section{Discussion}

\subsection{Result Analysis}

The results indicated enterprise employees' Vocational Delay of Gratification is positively related to job performance, this result is consistent with previous studies[5] [8]-[11] [13] [21]. We analyzed and summarized the following reasons: based on the expectations of the stage work and long-term career development, people will selectively choose taking pleasure in time or delayed attitude to adapt the job, which will produce some effect on work-related emotion (career satisfaction) and behavior (job performance). The employees who go after short-term interests are more inclined to be slack, which will directly affect their perception of work, resulting in no sense of the work or other negative attitudes, which will affect their job performance negatively at the same time. In the long term, compared with the high Vocational Delay of Gratification staff, low Vocational Delay of Gratification staff have lower occupation satisfaction and job performance; the staff who is willing to look forward to company's long-term benefits (rank, salary level, etc.), being able to give up instant gratification to achieve their long-term career goals, tend to use a better correct attitude to face returns (salary, skills training,

Table 2. Fitting index of vocational delay of gratification influence path model.

\begin{tabular}{cccccc}
\hline $\mathrm{X}^{2} / \mathrm{df}$ & CFI & TLI & IFI & NFI & RMSEA \\
\hline 2.489 & 0.972 & 0.980 & 0.972 & 0.974 \\
\hline
\end{tabular}

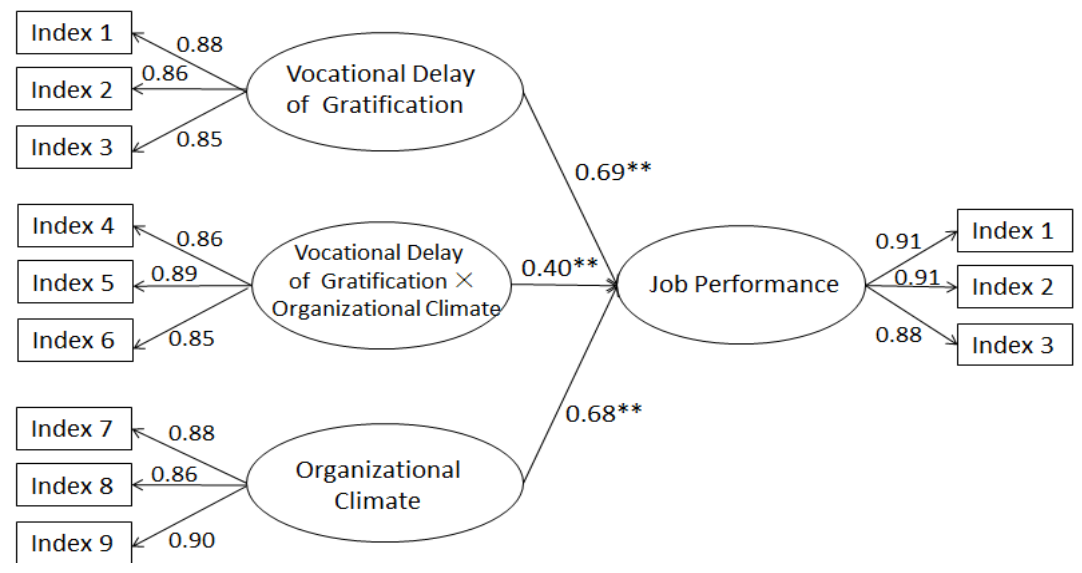

Figure 1. Structure model of vocational delay of gratification affecting on employee performance. 
promotion, etc.) of the organization. What's more, they can maintain a higher occupation satisfaction and have better job performance.

Meanwhile, on the basis of previous studies, this paper introduced a new environmental variable-organizational climate, which made up that delay of gratification field only focus on personal factors. The results validated the hypothesis that organizational climate acts as a moderator between Vocational Delay of Gratification and job performance. The mechanism under this result, from both theoretical and practical aspects, is as follows. Employees will perceive whether the current organizational climate is conducive to realize their original intentions when they decided to have vocational delay of gratification. How the cognition to organizational climate tally with expectation of achieving delay of gratification, will shows changes in the job performance in terms of behavior. In Chinese cultural context, interdependence and mutual cooperation, equal and harmonious working environment among people can act as a "lubricant" role of the organization, allowing employees to pursue their own career, and on the basis of this, make sure their position and organizational expectations, strive to enhance their own job performance and ultimately help to improve organizational performance [19].

\subsection{Implications}

Based on Chinese cultural background and realistic conditions, from the perspective of organizational climate, this paper focused on Vocational Delay of Gratification of employees, enriching the empirical research on vocational delay of gratification. Practical implications are as follows. Firstly, the result shows that the Vocational Delay of Gratification of employees is indicative of their job performance, and individuals can improve their professional ability of Vocational Delay of Gratification through self-control training, in order to improve their job performance, increasing occupational satisfaction and organizational competitiveness .Secondly, the organization should improve the objective environment, and then develop the overall goal of the organization, offering resource and providing a good organizational climate for employees to achieve good personal development. Meanwhile, organization is obliged to focus on their staff's psychological state, let them feel the supports and equity to improve their organizational commitment and satisfaction, and then promote the performance. Thirdly, managers ought to accurately know the status of the Vocational Delay of Gratification of employees, and select the employees who has a strong ability in keeping vocational delay of gratification. It's not only beneficial to retain talent, but more able to promote employee's job performance, making the employees' interest fit the enterprises' interests, gaining maximum benefit to the enterprise, which is beneficial to long-term development. Finally, the organization should pay more attention to the moderating effect of organizational climate, motivate staffs' work enthusiasm by creating the organizational climate that is consistent with the vocational delay of gratification, and then promote employee's job performance.

\section{Limitations and Directions for Future Research}

From the perspective of theory, this paper enriched Vocational Delay of Gratification theory, explored how interaction between person and the environment affect vocational delay of gratification. In practice, this study provides the inspirations for enterprise recruitment and selection, training and exploitation, employee psychological adjustment and organizational climate building and other human resources management. It can also guide employees or those who a researching for jobs to adjust their vocational delay of gratification, and provide a successful blueprint for their career. However, there are some limitations. The authority and normativity of local questionnaire are insufficient and there is still much room for improvement; the sample range is not large enough, further study can expand the sample range and use stratified sampling, improving the reliability of data analysis is imperative. What's more, the mutual influence among each variable dimension in this study needs further exploration, and in light of this, future study can explore the action mechanism of vocational delay of gratification, providing feasible proposals on enterprise personnel selection and employees' career planning.

\section{References}

[1] Reynolds, B. and Schiffbauer, R. (2005) Delay of Gratification and Delay Discounting: A Unifying Feedback Model of Delay-Related Impulsive Behavior. Psychological Review, 31, 659-679.

[2] Wang, Z., Liu, Y. and Yuan, D. (2012) Vocational Delay of Gratification. Advances in Psychological Science, 5, 705-714.

[3] Borman, W.C. and Motowidlo, S.J. (1993) Expanding the Criterion Domain to Include Elements of Contextual Per- 
formance. Personnel Selection in Organizations San Francisco: Jossey-Bass, 71-98.

[4] Borman, W. (1993) Progress toward at Astronomy of Managerial Performance Requirement. Human Performance, 6, 12-21. http://dx.doi.org/10.1207/s15327043hup0601_1

[5] Miller, M.J., Woehr, D.J. and Hudspeth, N. (2002) The Meaning and Measurement of Work Ethic: Construction and Initial Validation of a Multidimensional Inventory. Journal of Vocational Behavior, 60, 451-489. http://dx.doi.org/10.1006/jvbe.2001.1838

[6] Wang, Z. (2009) The Influence of Enterprise Staff Personality Variables on Job Involvement. Qufu Normal University, Jining.

[7] Liu, X., Hao, C., Chen, J. and Cui, H. (2007) The Influence of Organizational Career Management on Occupational Promise and Job Satisfaction: Vocational Delay of Gratification as a Mediator. Acta Psychologica Sinica, 4, 715-722.

[8] Kang, Y. (2009) The Relationship between Vocational Delay of Gratification and Career Self-Management. Shanxi University, Taiyuan.

[9] Cao, Y. (2012) The Influence of Employees’ Vocational of Gratification on Job Performance. Nanchang University, Nanchang.

[10] Kang, Y. (2013) The Moderating Effect of Vocational Delay of Gratification in Job Satisfaction. Tianjin Normal University, Tianjin.

[11] Sun, Y. (2013) A Study on the Relationship between Employees’ Psychological Capital and Job Performance: The Moderating Effect of Vocational Delay of Gratification. Anhui Normal University, Wuhu.

[12] Yan, X. (2011) The Influence of Goal Orientation on Job Performance: The Moderating Effect of Vocational Delay of Gratification. Shanxi University, Taiyuan.

[13] Zhang, X. (2014) The Vocational Delay of Gratification of Civil Servants and the Relation between It and the Job Performance. Xiamen University, Xiamen.

[14] Wang, Y., Yu, J. and Li, Y. (2012) Study on the Effective Mechanism of Organizational Climate on the Staff's Effectiveness. Psychological Exploration, 32, 188-192.

[15] Wu, Q. (2012) Research on Work Performance Impact of the Grass-Roots Civil Servants by Perceived Organizational Support and the Organization Climate. Xi'an University of Architecture and Technology, Xi'an.

[16] Shore, L.M. and Wayne, S.J. (1993) Commitment and Employee Behavior: Comparison of Affective Commitment and Continuance Commitment with Perceived Organizational Support. Journal of Applied Psychology, 78, 774-780. http://dx.doi.org/10.1037/0021-9010.78.5.774

[17] Pan, X., Qin, Q. and Tan, X. (2006) A Correlation Study of the Characteristics of College Students' Attribution of Study Success or Failure and Their Metal Health. Psychological Science, 29, 100.

[18] Lewin, K., Lippitt, R. and White, R.K. (1939) Patterns of Aggressive Behavior in Experimentally Created "Social Climates”. The Journal of Social Psychology, 10, 271-299.

[19] Schneider, B. (1975) Organizational Climates: An Essay. Personnel Psychology, 28, 447-479. http://dx.doi.org/10.1111/j.1744-6570.1975.tb01386.x

[20] Bock, G.-W., Lee, J.-N., Zmud, R.W. and Kim, Y.-G. (2005) Behavioral Intention Formation in Knowledge Sharing: Examining the Roles of Extrinsic Motivators, Social-Psychological Forces, and Organizational Climate. MIS Quarterly, 29, 87-111.

[21] Wen, L. (2014) The Influence of Vocational Delay of Gratification on Job Performance and Career Success: The Effect of Vocational Delay of Gratification and Learning Goal Orientation. Human Resource Development of China, 19, 6773. 